\title{
Lower facial contouring surgery using a novel method: M-genioplasty
}

\author{
June Bok Lee ${ }^{1}$, Jin Woo Han ${ }^{2}$, Jun Hyung Park ${ }^{3}$, Kyung Hee Min ${ }^{2}$ \\ ${ }^{1}$ Mega Plastic Surgery Clinic, Seoul; ${ }^{2}$ Department of Plastic and Reconstructive Surgery, Eulji General Hospital, Eulji University School of \\ Medicine, Seoul; ${ }^{3}$ THE PLAN Plastic Surgery Clinic, Seoul, Korea
}

Background Mandibular contouring surgery to produce a more slender and small face has become popular, especially in East Asia. Narrowing genioplasty should be simultaneously performed with mandibular angle resection to achieve satisfactory results. In Korea, T-genioplasty has been frequently performed for chin narrowing. The authors developed a new, safe, and reliable method, termed M-genioplasty, that can provide a more slender and attractive lower face.

Methods From June 2013 to December 2017, 36 patients underwent M-genioplasty with mandibular angle resection for lower facial contouring. Horizontal and vertical osteotomies were performed obliquely. The resected bone segments were wedge-shaped. The remaining two bone segments were rotated and approximated centrally. The lateral mandible bony stepoff was trimmed off for mandibular angle resection.

Results In all patients, the facial contour sufficiently improved, and most patients were satisfied with the outcome. No severe complications took place during postoperative follow-up. Conclusions M-genioplasty can provide more mandibular angle resection and can create a more acute chin angle without bone resorption than other methods, including T-genioplasty. M-genioplasty with mandibular angle resection is a safer, more accurate, and more reliable method for lower facial contouring.

Keywords Mandible / Chin / Genioplasty
Correspondence: Kyung Hee Min Department of Plastic and Reconstructive Surgery, Eulji General Hospital, Eulji University School of Medicine, 68 Hangeulbiseong-ro, Nowon-gu, Seoul 01830, Korea Tel: +82-2-970-8255 Fax: +82-2-978-4772 E-mail:mkh797@hanmail.net

This work was presented at Aesthetic Plastic Surgery 2017 (KSAPS) on April 1-2, 2017, in Seoul, Korea.

\section{INTRODUCTION}

A square-shaped and broad lower face is considered unattractive and less feminine in East Asia. Many people therefore desire to have a more slender and smaller face. Therefore, mandibular contouring surgery is increasingly popular in East Asia [1-6].

The conventional method used in patients with a squareshaped mandible is mandibular angle resection. However, some patients do not achieve a satisfactory result with mandibular an- gle resection alone $[7,8]$. The chin is an important component of the lower face, along with the mandibular angle. For patients with a wide and flat chin, additional chin-modifying surgery is needed to achieve a more slender and attractive lower face. Therefore, narrowing genioplasty is commonly performed simultaneously with mandibular angle resection. Various methods have been introduced and used for lower facial contouring [1-6,9-12]. Among these methods, the so-called T-genioplasty with mandibular angle resection is commonly performed in Ko- 
rea $[1,10,11]$. We developed a novel and reliable method, termed M-genioplasty, that can provide a more slender and balanced contouring of the lower face.

\section{METHODS}

From June 2013 to December 2017, 36 patients underwent lower facial contouring surgery through M-genioplasty with mandibular angle resection. Among these 36 patients, 32 were women and four were men. The age of the patients ranged from 20 to 36 years, with a mean age of 26 years. One patient had undergone mandibular angle resection at another plastic surgery clinic. Among them, 27 patients underwent reduction malarplasty simultaneously, and 10 patients underwent adjuvant liposuction around the chin. Preoperatively, 3-dimensional computed tomography images, cephalometric radiographs, and clinical photographs of patients were evaluated. The extent of resection was determined according to the chin shape and preferences of each patient, based on preoperative clinical data.

\section{Surgical procedure}

All operations were performed under general anesthesia through orotracheal intubation.

The mid-symphyseal area was exposed through a conventional intraoral vestibular incision and subperiosteal dissection. The

\section{Fig. 1. Design of osteotomy lines in M-genioplasty}

The shadowed bone segments shown in red were removed. The remaining two bone segments were rotated centrally and fixed. The resulting lateral bony step-off was trimmed off.
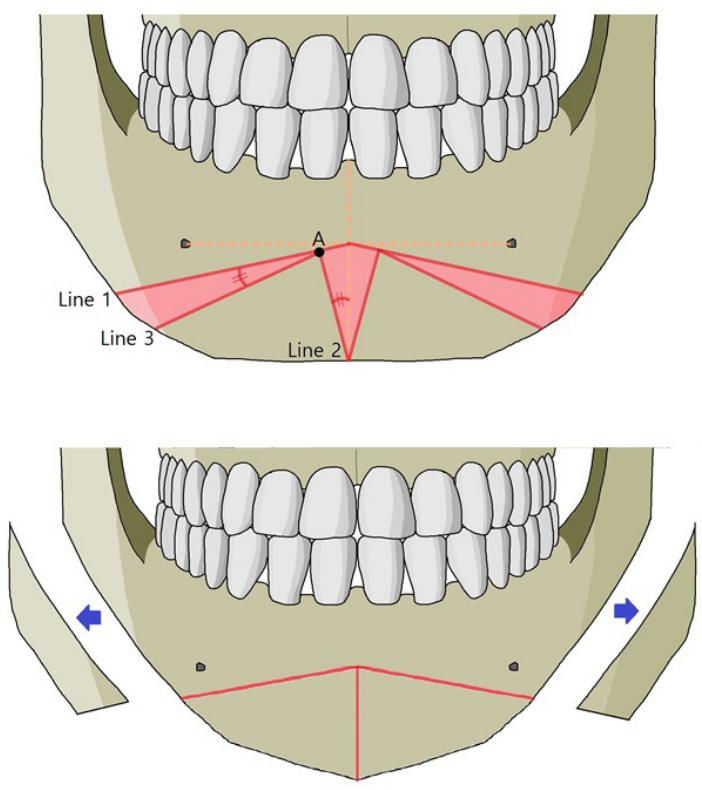

soft tissue of the chin was preserved to the greatest extent possible to maintain sufficient blood supply to bony segments and to produce the greatest possible chin narrowing effect. The osteotomy lines were designed as shown in Figs. 1 and 2. Due to the shape of the osteotomy lines, we named this method M-genioplasty. Line 1 started at the mid-symphyseal line between the mental foramina, and continued downwards to about $5 \mathrm{~mm}$ below the mental foramen. Then, point $A$ was determined on line 1. Line 2 was drawn from point $A$ to the mid-symphyseal line on the lower border of the mandible. Line 3 was drawn from point $\mathrm{A}$ to the lower border of the mandible at an angle that was same as the angle between line 2 and the mid-symphyseal line. Finally, the angle between line 1 and line 3 was equal to the angle between line 2 and the mid-symphyseal line. In patients with lower face asymmetry, the position of point A was different. As a result, the angles on both sides were different. After the osteotomies were completed, the lateral and central bone segments were removed. The remaining 2 bone segments were approximated centrally and fixed with microplates and screws. The lateral bony step-off on the lower border of the mandible was due to narrowing genioplasty. To remove this bony step-off and to obtain a more slender line of the lower face, the lateral bony edges were trimmed off (Fig. 3). Resection of bony edges was extended to the angle of the mandible. In M-genioplasty, the location of point A determines the amount of bone to be resected. If point $\mathrm{A}$ is located too far from the mid-symphyseal line, the length of line 3 becomes short. Then, when lateral bony edge resection is performed later, it comes too close to the mental foramen and the risk of inferior alveolar nerve damage increases. The position of point $\mathrm{A}$ and the amount of lateral bony edge re-

\section{Fig. 2. Intraoperative view}

Osteotomy lines of M-genioplasty were marked.

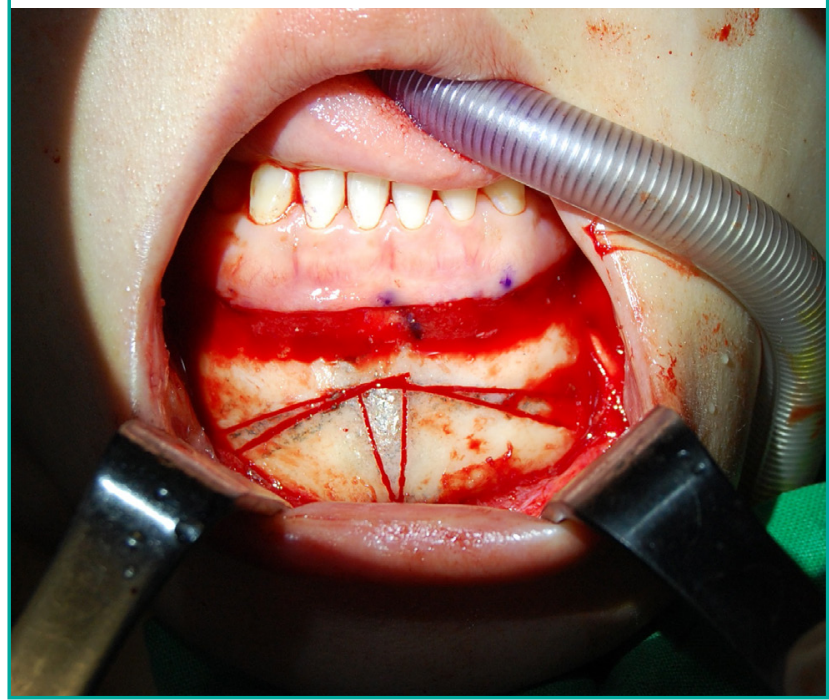


Fig. 3. Three-dimensional computed tomography images

$(A, B)$ Preoperative three-dimensional computed tomography (3D-CT) images. (C, D) Onemonth postoperative 3D-CT images after Mgenioplasty with mandibular angle resection and reduction malarplasty.
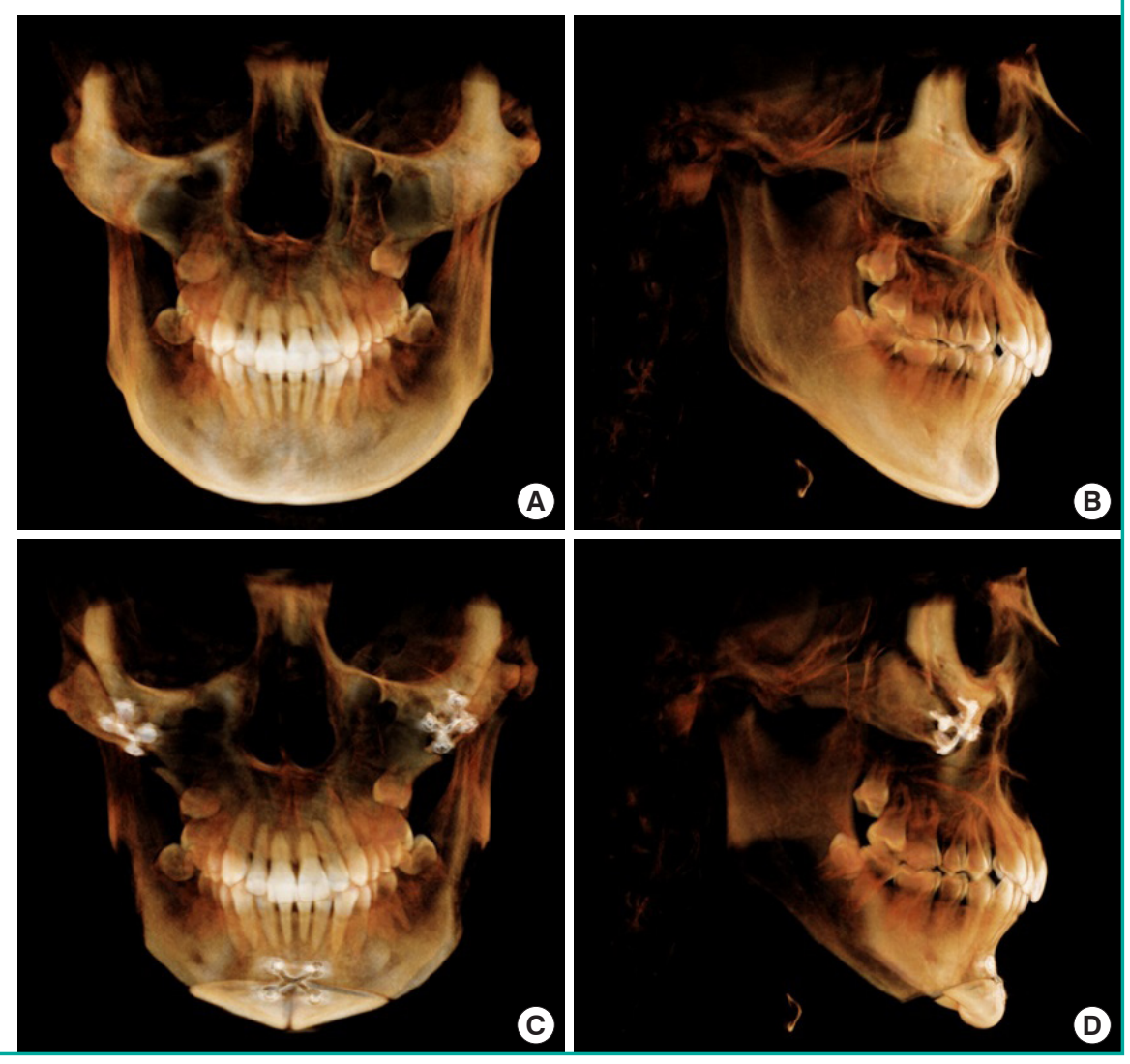

section were determined preoperatively through clinical assessment and discussion with the patients.

\section{RESULTS}

The angle between line 1 and line 3 was approximately $10^{\circ}$ to $15^{\circ}$. All the patients were satisfied with a more slender and smaller face postoperatively. The follow-up period ranged from 1 to 59 months, with an average follow-up period of 5.8 months. No severe complications occurred during postoperative followup (Figs. 4 and 5).

\section{DISCUSSION}

In addition to the mandible angle, the chin, defined superiorly by the labiomental sulcus and inferiorly by the gnathion, is an important component that determines the lower face $[1,13]$.

Therefore, narrowing genioplasty has been simultaneously performed with mandibular angle resection in lower facial contouring surgery [1-6,9-12]. Recently, in Korea, T-genioplasty with mandibular angle resection has been frequently performed. In T-genioplasty, one horizontal osteotomy and two vertical osteotomies are performed. The mid-symphyseal strip is then re- sected. The remaining lateral bone segments are approximated to the midline and fixed. The resulting lateral bony step-off is resected for mandibular angle reduction $[1,10,11]$. Unlike T-genioplasty, in our M-genioplasty, a horizontal osteotomy is performed obliquely. The lateral and central bony segments are resected in a wedge shape, and the remaining bone segments are then rotated and approximated to the midline. This can create a more acute chin angle, with a V-line, than T-genioplasty.

The angle of resection should be individualized depending on the chin shape and the patient's needs. Of note, for an asymmetric lower face, the angles on both sides should be different. In this respect, M-genioplasty is more accurate and enables an easier correction of asymmetry than other methods. Also, as with other methods, M-genioplasty can be performed for chin advancement if needed.

In T-genioplasty, to obtain a more acute chin angle, the midsymphyseal strip to be resected is designed to be larger. Then, the remaining lateral bone segments become too small, which increases the risk of bone resorption. However, in M-genioplasty, the remaining bone segments are relatively large, because both the middle bone segment and the lateral bone segments are resected in a wedge shape and the remaining bone segments are rotated. Therefore, there is a relatively low risk of bone re- 


\section{Fig. 4. Case 1}

( $A, B)$ Preoperative photograph of a 36-yearold woman. (C, D) Three-month postoperative photograph after M-genioplasty with mandibular angle resection and reduction malarplasty.
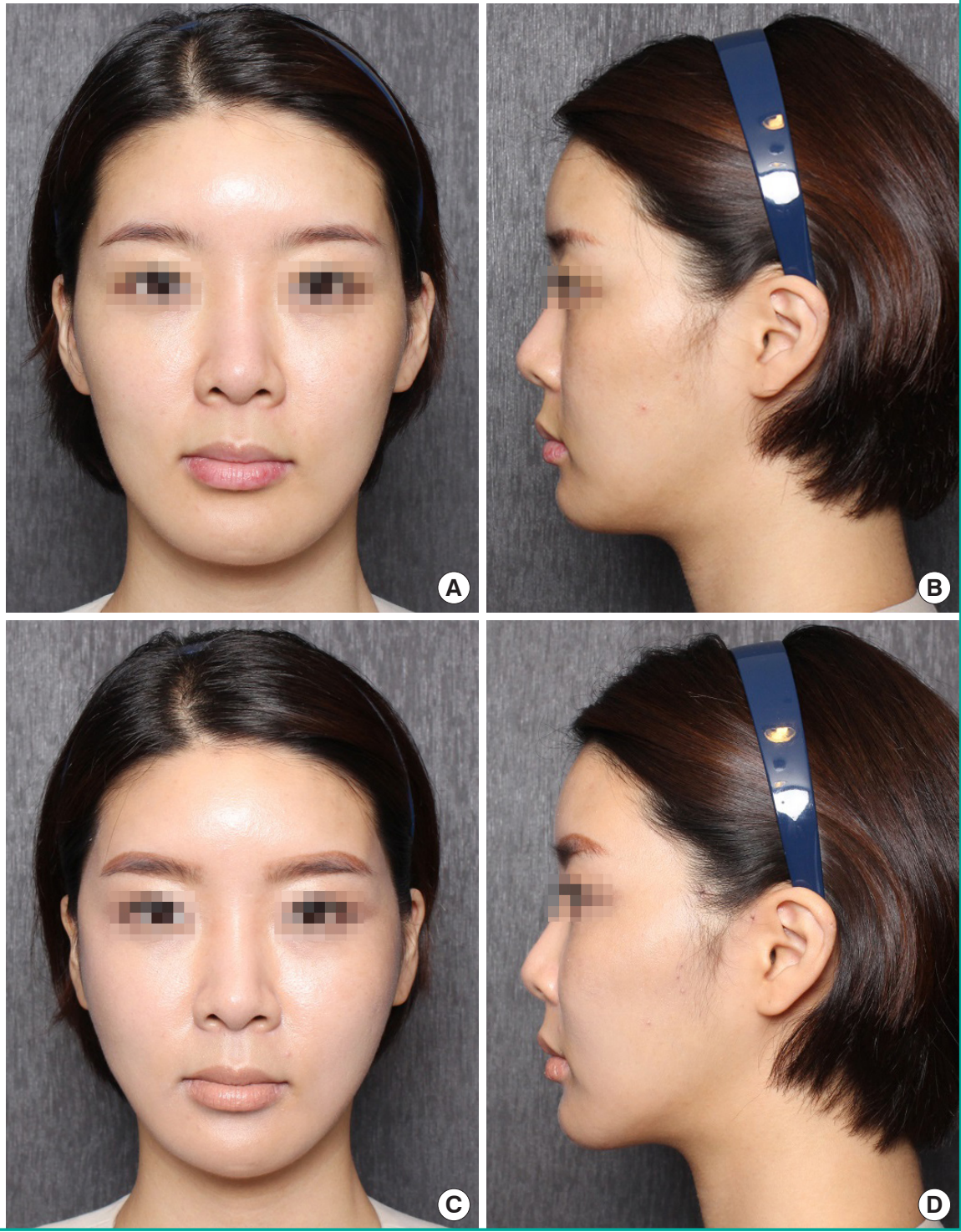

sorption in M-genioplasty.

Similar to our method, Keyhan et al. [12] introduced the zigzag genioplasty for narrowing of the chin. In both methods, the oblique osteotomy lines are similar. However, the location and amount of resected bone segments are different. In zigzag genioplasty, the resected bone segments are smaller than in our method. Therefore, our method is more effective for narrowing of the chin.

Farina et al. [14] introduced the M-shaped genioplasty. The name of this procedure is almost identical to that of our procedure. However, the M-shaped genioplasty is for sagittal and vertical chin augmentation, unlike the purpose of our M-genioplasty.

In our cases, no severe complications occurred except for minor complications, including transient lower lip numbness.
These complications resolved quickly.

However, when large bone segments are resected and rotated, the lateral side of the remaining bone segment may come closer to the mental foramen, which may increase the risk of inferior alveolar nerve injury during mandibular angle resection.

Therefore, when designing the osteotomy lines and angles, the course of the inferior alveolar nerve should be considered.

For correction of a square-shaped lower face, the slope of the mandibular angle and the chin shape should be considered simultaneously. Our M-genioplasty with mandibular angle resection is very useful, especially in patients who want a much more slender lower face, with a V-line. Therefore, the M-genioplasty with mandibular angle resection is a safer, more accurate, and more reliable method for lower facial contouring. 


\section{Fig. 5. Case 2}

$(A, B)$ Preoperative photograph of a 27-yearold woman. (C, D) Thirteen-month postoperative photograph after M-genioplasty with mandibular angle resection and reduction malarplasty.
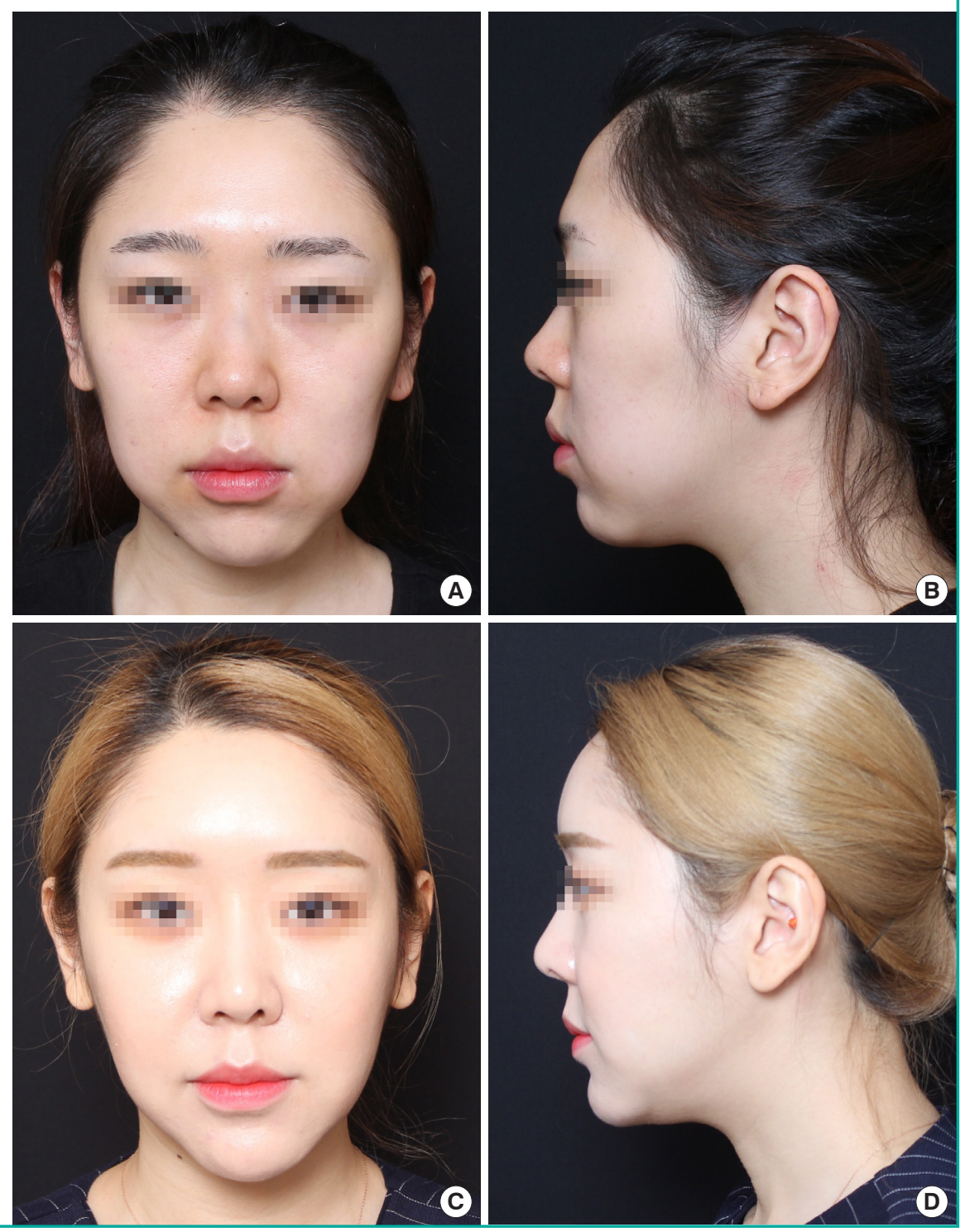

\section{NOTES}

\section{Conflict of interest}

No potential conflict of interest relevant to this article was reported.

\section{Ethical approval}

The study was approved by the Institutional Review Board of Eulji University Eulji Medical Center (IRB No. EMCIRB 18-95) and performed in accordance with the principles of the Declaration of Helsinki. Written informed consents were obtained.

\section{Patient consent}

The patients provided written informed consent for the publica- tion and the use of their images.

\section{REFERENCES}

1. Park S, Noh JH. Importance of the chin in lower facial contour: narrowing genioplasty to achieve a feminine and slim lower face. Plast Reconstr Surg 2008;122:261-8.

2. Lee S, Kim BK, Baek RM, et al. Narrowing and lengthening genioplasty with pedicled bone graft in contouring of the short and wide lower face. Aesthetic Plast Surg 2013;37: 139-43.

3. Lee TS, Kim HY, Kim TH, et al. Contouring of the lower face by a novel method of narrowing and lengthening genioplasty. Plast Reconstr Surg 2014;133:274e-282e. 
4. Lee SW, Ahn SH. Angloplasty revision: importance of genioplasty for narrowing of the lower face. Plast Reconstr Surg 2013;132:435-42.

5. Li J, Hsu Y, Khadka A, et al. Contouring of a square jaw on a short face by narrowing and sliding genioplasty combined with mandibular outer cortex ostectomy in orientals. Plast Reconstr Surg 2011;127:2083-92.

6. Li J, Hsu Y, Khadka A, et al. Surgical designs and techniques for mandibular contouring based on categorisation of square face with low gonial angle in orientals. J Plast Reconstr Aesthet Surg 2012;65:e1-8.

7. Yang DB, Song HS, Park CG. Unfavorable results and their resolution in mandibular contouring surgery. Aesthetic Plast Surg 1995; 19:93-102.

8. Baek SM, Baek RM, Shin MS. Refinement in aesthetic contouring of the prominent mandibular angle. Aesthetic Plast Surg 1994; 18:283-9.

9. Chen T, Khadka A, Hsu Y, et al. How to achieve a balanced and delicate lower third of the face in Orientals by mandibu- lar contouring. J Plast Reconstr Aesthet Surg 2013;66:4756.

10. Grime PD, Blenkinsopp PT. Horizontal-T genioplasty: a modified technique for the broad or asymmetrical chin. Br J Oral Maxillofac Surg 1990;28:215-21.

11. Jegal JJ, Kang SJ, Kim JW, et al. The utility of a three-dimensional approach with T-shaped osteotomy in osseous genioplasty. Arch Plast Surg 2013;40:433-9.

12. Keyhan SO, Khiabani K, Hemmat S, et al. Zigzag genioplasty: a new technique for 3-dimensional reduction genioplasty. Br J Oral Maxillofac Surg 2013;51:e317-8.

13. Taub DI, Jacobs JM, Jacobs JS. Anthropometry, cephalometry, and orthognathic surgery. In: Neligan PC, editor. Plastic surgery. vol. 2, 3rd ed. Philadelphia: Saunders; 2012. p. 360.

14. Farina R, Valladares S, Aguilar L, et al. M-shaped genioplasty: a new surgical technique for sagittal and vertical chin augmentation: three case reports. J Oral Maxillofac Surg 2012;70:1177-82 